\title{
Avaliação da reatividade de rejeitos de caulim para uso como precursor geopolimérico
}

\section{Evaluation of reactivity of kaolin tailings for use as geopolymeric precursor}

\author{
Cléo Márcio de Araújo Santana ${ }^{1}$, Cláudio Mesquita Campinho de Azevedo ${ }^{1}$, Juliana Bastos de \\ Oliveira Lima ${ }^{1}$, Lívia Gonçalves Machado ${ }^{1}$, Luccas Feuchard Mansur ${ }^{1}$, Eliane Fernandes Côrtes \\ Pires $^{1}$, Elie Chahdan Mounzer ${ }^{1}$, Felipe José da Silva ${ }^{12}$ *
}

\begin{abstract}
RESUMO
O presente trabalho é um estudo preliminar das potencialidades de emprego de metacaulins obtidos a partir da calcinação controlada de rejeitos de beneficiamento de caulins comerciais, na produção de geopolímeros para aplicações estruturais. Os resultados de caracterização mostraram composições químicas similares, mas diferenças significativas de granulometria entre os seis tipos de rejeito estudados. Análises por microscopia eletrônica de varredura (MEV) e difração de raios X (DRX) foram realizadas para investigar a morfologia das partículas, confirmar as composições química e mineralógica e verificar se a calcinação foi capaz de amorfizar a estrutura da caulinita. As amostras calcinadas foram comparadas entre si e com uma amostra de referência e usadas como precursor aluminossilicato em uma formulação padrão, tendo sua consistência em estado fresco e a resistência à compressão no estado endurecido determinadas. Os resultados destacaram apenas duas amostras calcinadas consideradas em conformidade com o padrão, embora se considere que o beneficiamento por moagem e a calcinação por tempo mais longo conduza à resultados mais promissores.
\end{abstract}

Palavras-chave: Rejeitos de caulim; Metacaulim; Geopolímero; Blendas.

\begin{abstract}
The present work is a preliminary study of the potential use of metakaolins obtained from the controlled calcination of commercial kaolin tailings, in the production of geopolymers for structural applications. The characterization results showed similar chemical compositions, but significant differences in particle size among the six types of tailings studied. Scanning electron microscopy (SEM) and X-ray diffraction (XRD) analyzes were performed to investigate the morphology of the particles, confirm the chemical and mineralogical compositions and verify if the calcination was able to amorphize the kaolinite structure. The calcined samples were compared with each other and with a reference sample and used as an aluminosilicate precursor in a standard formulation, with its freshness strength and hardened compressive strength determined. The results highlighted only two calcined samples considered in compliance with the standard, although milling processing and longer-term calcination are considered to lead to more promising results.
\end{abstract}

Keywords: Kaolin tailings; Metakaolin; Geopolymer; Blends.

\footnotetext{
${ }^{1}$ Universidade Federal Fluminense - UFF/Campus Praia Vermelha.

${ }^{2}$ Instituto Federal do Rio de Janeiro - IFRJ/Campus Paracambi. *E-mail: felipe.silva@ifrj.edu.br
} 


\section{INTRODUÇÃO}

A indústria de papel e tinta usa caulins de elevada alvura e pureza de composição, o que exige que o minério seja submetido a um criterioso processamento de separação das frações mais finas e leves do minério, especialmente a caulinita, dos demais constituintes, fazendo com que se gerem elevados volumes de rejeito. Mesmo sendo considerado rejeito, ainda contém razoáveis quantidades de filossilicatos e outros argilominerais, que podem, juntos, ser aproveitados como fonte precursora na síntese de geopolímeros e, também, como pozolana para concreto de cimento Portland. Atualmente, as mineradoras propõem o aproveitamento desses rejeitos para a fabricação de massas cerâmicas de grés sanitário. Segundo dados da Agência Nacional de Mineração (ANM), as principais reservas de caulim que existem no Brasil, cerca de 98\%, estão localizadas nos estados do Pará e Amazonas, que totalizaram aproximadamente 7 bilhões de toneladas no ano de 2017 (CAMPOS et al., 2018).

Como é sabido, o metacaulim é uma pozolana artificial cuja aplicação em concreto de cimento Portland é relativamente recente. Difere das pozolanas tradicionais por possuir elevado teor de alumínio $\left(\mathrm{SiO}_{2} / \mathrm{Al}_{2} \mathrm{O}_{3} \sim 1,3\right)$, o que, de certa forma, contribui para a aceleração da reação de hidratação do cimento Portland, minimizando o retardo no tempo de pega e conduzindo à resistências iniciais mais próximas das esperadas. Outro benefício, senão o maior, é a formação de C-S-(A)-H amorfo e cristalino, a Strätlingita $\left(\mathrm{C}_{2} \mathrm{ASH}_{8}\right)^{3}$, que ajuda a aumentar a compacidade da matriz e a diminuir o teor de hidróxido de cálcio livre.

O metacaulim é uma pozolana Classe $\mathrm{N}$, segundo classificação da ASTM C618:1994a,

“...Pozolana natural ou natural calcinada com propriedades tais como as de algumas terras diatomáceas (diatomitos); calcedônios e xistos opalinos; tufos e cinzas vulcânicas ou de pedrapomes, processadas ou não por calcinação e ainda vários materiais que requerem calcinação para induzir propriedades satisfatórias, tais como algumas argilas e xistos..." (ASTM, 2019).

As condições impostas por estas especificações geralmente levam em conta a densidade, a finura e a composição química. A finura costumava ser definida pelo resíduo

\footnotetext{
${ }^{3}$ Costuma-se, em química do cimento, adotar abreviações: $\mathrm{C}=\mathrm{CaO} ; \mathrm{S}=\mathrm{SiO}_{2} ; \mathrm{A}=\mathrm{Al}_{2} \mathrm{O}_{3} ; \mathrm{H}=\mathrm{H}_{2} \mathrm{O}$.
} 
na peneira com abertura de malha de 0,044 mm (malha 325) - máx. 34\% (antiga NBR 9202:1995) e pelos mínimos de superfície específica determinada pelo método da permeabilidade ao ar pelo aparelho de Blaine (NBR 16372:2015), de $280 \mathrm{~m}^{2} / \mathrm{kg}$. Embora as normas limitem valores tão baixos para a superfície específica, a boa pozolana deve possuir superfícies três a cinco vezes superiores a estas, da ordem de 900 a $1500 \mathrm{~m}^{2} / \mathrm{kg}$. No caso das pozolanas artificiais e de algumas naturais há necessidade de cominuição por não apresentarem superfícies tão elevadas. As pozolanas artificiais ficam aglomeradas após o tratamento térmico e algumas pozolanas naturais apresentam a forma detrítica ou mais ou menos aglomerada (SANTOS, 1975).

Como os geopolímeros são poli-óxido-aluminossilicatos obtidos a partir da dissolução e polimerização de óxido-aluminossilicatos em ambiente aquoso altamente alcalino e o metacaulim (metacaulinita) é um óxido-aluminossilicato, este, por conveniência, tem sido o mais utilizado nas pesquisas para obtenção de cimentos geopoliméricos, seguido pelas cinzas volantes. Para ser empregado na geopolimerização, o óxido-aluminossilicato deve apresentar os cátions alumínio em número de coordenação IV, ocupando posição tetraédrica em relação ao oxigênio. Alguns exemplos de minerais que depois de calcinados atendem a essa exigência básica são a alusita, caulinita, litomarga, paracaulinita, haloisita, amesita e a chamosita (DAVIDOVITS, 1991). A metacaulinita é a principal fonte de alumínio para o geopolímero, sendo este átomo o responsável pelas ligações cruzadas e pela configuração da sua rede tridimensional. Contudo, a reatividade depende não só do ambiente químico do $\mathrm{Al}$, como também da superfície específica do pó (finura) e do teor de impurezas, tais como o $\mathrm{Fe}_{2} \mathrm{O}_{3}, \mathrm{TiO}_{2}$ e $\mathrm{SiO}_{2}$, que ocorrem comumente sob a forma de ilmenita, rutilo, anatásio e quartzo nos caulins secundários (SANTOS, 1992). Como a geopolimerização ocorre a partir da destruição e recombinação das cadeias aluminossilicato da caulinita desordenada (metacaulinita) pela ação dos íons $\mathrm{OH}^{-}$e dos álcalis, especificamente nos sítios contendo alumínio, qualquer impedimento a esta reação, tais como o aprisionamento ou insuficiência de íons ou a substituição por átomos de impureza na estrutura original da caulinita, podem modificar a cinética das reações de geopolimerização e até mesmo inviabilizar a obtenção de um geopolímero com propriedades estruturais (KIVENTERÄ, 2020). O presente trabalho é um estudo preliminar das potencialidades de emprego de metacaulins obtidos a partir da calcinação controlada de subprodutos do beneficiamento de minérios de caulim da Região Amazônica, na produção de geopolímeros para 
aplicações estruturais. A investigação partiu do interesse de duas mineradoras de caulim, em prospectar o mercado de aditivos minerais (pozolanas) para concretos de cimento Portland e de matéria prima para geopolímeros, com o objetivo de identificar aqueles com as características que melhor atendem aos requisitos para estas aplicações.

\section{MATERIAIS E MÉTODOS}

Foram recebidas seis amostras de rejeito de caulim, coletadas em duas mineradoras distintas, ambas juntas a jazidas localizadas no estado do Pará. A composição química é mostrada na Tabela 1, juntamente com uma amostra padrão, préaprovada, usada neste estudo como comparativo de desempenho (KStd), oriunda de jazida localizada no estado do Rio Grande do Norte.

Tabela 1 - Composição química e propriedades físicas das amostras estudadas

\begin{tabular}{c|c|c|c|c}
\hline Material & $\mathbf{S i O}_{\mathbf{2}}$ & $\mathbf{A l}_{\mathbf{2}} \mathbf{O}_{\mathbf{3}}$ & $\mathbf{T i}_{\mathbf{2}} \mathbf{O}$ & $\mathbf{F e}_{\mathbf{2}} \mathbf{O}_{\mathbf{3}}$ \\
\hline KStd $^{*}$ & 45,2 & 41,43 & 1,25 & 2,31 \\
\hline KAP* $^{*}$ & 43,5 & 36,0 & 1,24 & 1,91 \\
\hline KCT $^{* *}$ & 46,4 & 38,8 & 0,28 & 0,22 \\
\hline KCS $^{*}$ & 44,3 & 37,1 & 0,63 & 0,67 \\
\hline KDR $^{*}$ & 43,3 & 36,7 & 1,27 & 1,11 \\
\hline KFL $^{*}$ & 45,3 & 37,1 & 0,64 & 0,57 \\
\hline KPX* & 44,7 & 37,3 & 0,73 & 0,61 \\
\hline * Obtida por EDS; ** Dados do fornecedor
\end{tabular}

Fonte: Os autores

As amostras, como recebidas, foram secas em estufa a $110^{\circ} \mathrm{C}$ por $24 \mathrm{~h}$ e resfriadas ao ar, conforme a ASTM C311:1994a. Em seguida, foram acondicionadas em frascos de plástico com tampa selada (Fig. 1). A distribuição granolomética foi realizada por peneiramento a seco, em peneirador mecânico, em peneiras de abertura de malha de $(4,8$; $2,4 ; 1,2 ; 0,6 ; 0,3 ; 0,15 ; 0,075)$ mm e fundo, conforme a NBR NM 248:2003.

Análises da morfologia das partículas e a composição química por EDS foram obtidas em um microscópio eletrônico de varredura (MEV) da marca JEOL, modelo 5800 LV, operando com filamento de tungstênio a $25 \mathrm{kV}$ e distância de trabalho de $20 \mathrm{~mm}$. As amostras foram recobertas por carbono para torná-las condutoras. Foi utilizado um difratômetro de raios X (DRX), marca Bruker, modelo D2 Phaser, operando com radiação $\mathrm{Cu}-\mathrm{K}_{\alpha}$ para identificar os minerais e argilominerais presentes nas amostras de rejeito de caulim, assim como para confirmar a amorfização obtida pela processo de calcinação em 
forno mufla, fixado em $850{ }^{\circ} \mathrm{C} / 2 \mathrm{~h}$, com base em estudos anteriores de calcinação da amostra padrão.

Figura 1 - Acondicionamento das amostras

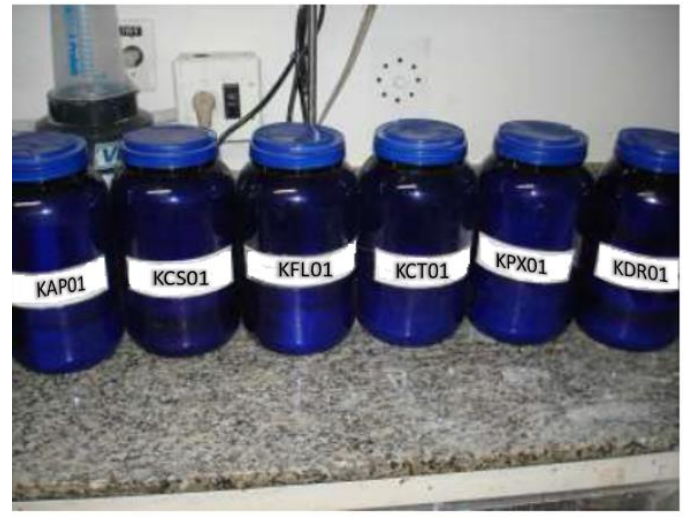

Fonte: Os autores

As amostras de rejeito caulim calcinadas (metacaulim) foram caracterizadas quanto à massa específica, pelo método do permeabilímetro de Blaine (NBR 16372:2015) e quanto à área específica, pelo frasco volumétrico de Le Chatelier (NBR 16605:2017).

A formulação adotada neste estudo comparativo de desempenho, foi de um geopolímero do tipo polisiloxossialato de sódio, potássio e cálcio (Na,K,Ca-PSS) com relação $\mathrm{Si} / \mathrm{Al}=3$, usando, como referência, o metacaulim Padrão, uma solução catalisadora composta por silicato de sódio e hidróxido de potássio (Catalisador A) e uma mistura de pós, de hidróxido de cálcio e óxido-aluminossilicato de cálcio (Catalisador B). As quantidades dos reagentes e do agregado são mostradas na Tabela 2, e a curva de evolução da resistência à compressão (RC) é mostrada na Figura 2.

Tabela 2 - Formulação de Referência*

\begin{tabular}{c|l|c|c|l|c}
\hline & \multicolumn{1}{|c|}{ Material } & Massa $(\mathrm{g})$ & & \multicolumn{1}{|c|}{ Material } & Massa (g) \\
\hline 1 & Metacaulim (MKStd)** & 104,50 & 4 & Água & 49,86 \\
\hline 2 & Catalisador A (SSHP691) & 168,16 & 5 & Areia Lavada (ARL744) & 576,38 \\
\hline 3 & Catalisador B (C3H264) & 62,38 & & & \\
\hline
\end{tabular}

Equip. Utilizados: Argamassadeira, Estufa $\left(65^{\circ} \mathrm{C} / 4 \mathrm{~h}\right)$, Prensa Hidráulica capac. 100t.

* Esta formulação apresentou $\mathrm{RC}_{65}{ }^{\circ} \mathrm{C} / 4 \mathrm{~h}=30 \pm 2 \mathrm{MPa}$ e Tempo de início de pega $=30$ minutos. ** Amostra Padrão de referência, Superfície Específica Blaine $=1.306,11 \mathrm{~m}^{2} / \mathrm{kg}$.

Fonte: Os autores

Quando curada em estufa a $65^{\circ} \mathrm{C} / 4 \mathrm{~h}$, atinge $\mathrm{RC}=30 \pm 2 \mathrm{MPa}$, cerca de $93 \%$ da resistência aos 28 dias da argamassa geopolimérica curada a temperatura ambiente, apresentando características reológicas e propriedades mecânicas que atendem às 
especificações para aplicação em pré-moldados (BARANI et al., 2018). O agregado miúdo (areia com módulo de finura igual a 2,5) foi separado em quatro frações granulométricas de mesma massa, passante e retida, respectivamente, nas peneiras 2,4 mm-1,2 mm; 1,2 mm-0,6 mm; 0,6mm-0,3mm e 0,3 mm-0,15 mm.

Figura 2 - Variação da resistência à compressão com a idade. Cura a temperatura ambiente e térmica

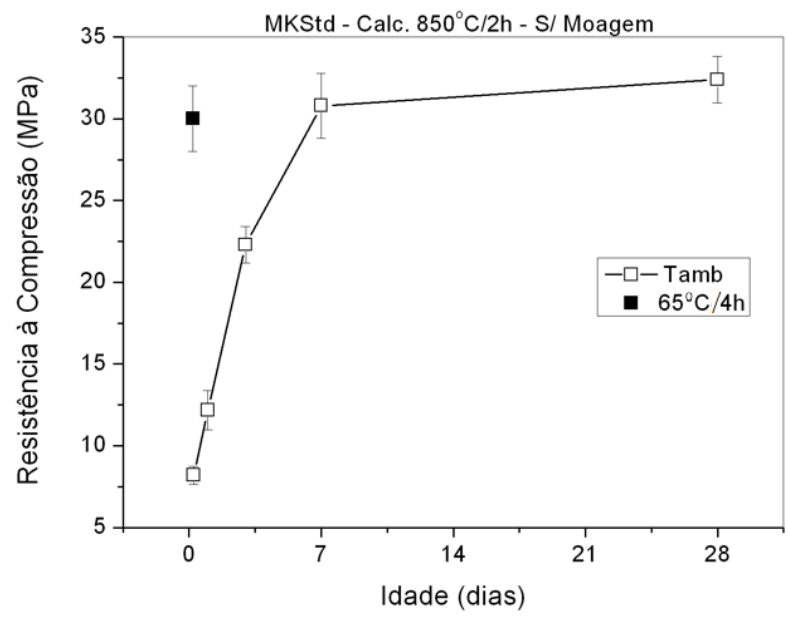

Fonte: Os autores

\section{RESULTADOS E DISCUSSÃO}

A análise granulométrica dos caulins até a malha nº $200(0,075 \mathrm{~mm})$ é apresentada na Figura 3. Apesar da composição química similar, pode-se perceber claramente que se tratam de caulins extremamente diferentes entre si, em termos de granulometria. Aquele, cuja granulometria mais se aproxima da amostra Padrão é o caulim KDR (Fig. 3).

As curvas granulométricas das demais amostras afastam-se do perfil apresentado pela amostra padrão, no que se refere às frações analisadas. Sabe-se, no entanto, que a análise granulométrica em via seca não permite distinguir partículas individuais de aglomerados, nem tampouco separar as partículas ultrafinas aderidas às superfícies das partículas maiores. A análise em granulômetro a laser ou em sedígrafo (raios X), realizada em meio líquido e sob ação de dispersantes, permite distinguir tais partículas individuais de aglomerados e completam a análise granulométrica, atingindo a escala coloidal (LIMA et al., 2021).

Figura 3 - Distribuição granulométrica das amostras de rejeito de caulim 


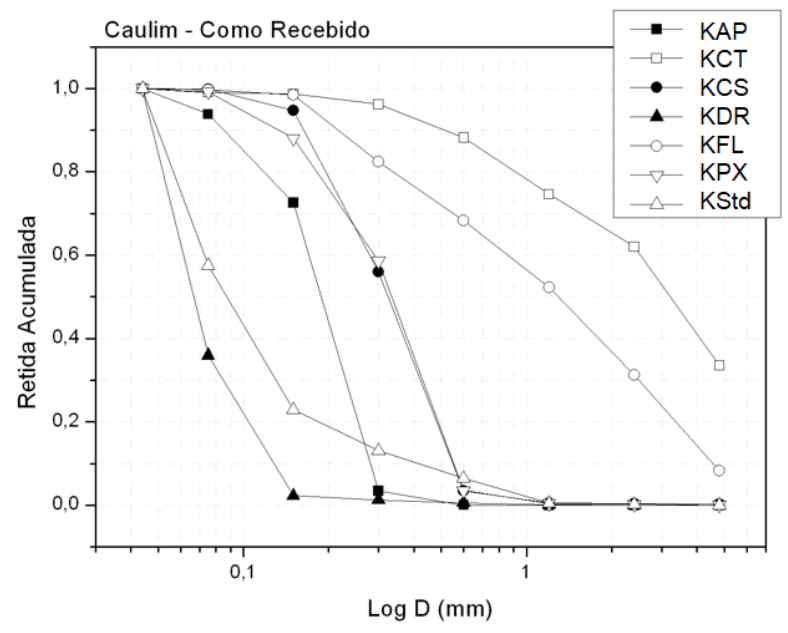

Fonte: Os autores

A Tabela 3 mostra a distribuição granulométrica da amostra Padrão, obtida por sedígrafo.

Apesar da limitação deste estudo, em termos práticos, foi possível distinguir e comparar satisfatoriamente as diferentes amostras entre si e com a amostra padrão.

Tabela 3 - Distribuição granulométrica do caulim Padrão (KStd) (< malha 400)

\begin{tabular}{c|c}
\hline$(\%)$ retida, em massa & Diâmetro esférico equivalente $(\mu \mathrm{m})$ \\
\hline 0,8 & $<1$ \\
\hline 52,0 & 2 \\
\hline 27,0 & 3 \\
\hline 16,5 & 4 \\
\hline 2,5 & 5 \\
\hline 1,2 & $>5$ \\
\hline
\end{tabular}

Fonte: Os autores

As Figuras 4 a 10 mostram as microestruturas obtidas em MEV, dos diversos resíduos de caulim estudados. O objetivo foi identificar a presença de aglomerados de partículas, inferir sobre a distribuição de tamanhos, morfologia das partículas individuais e dos aglomerados, presença de partículas estranhas e, com uso do EDS, identificar (qualitativamente) os elementos presentes na amostra. Confirmou-se, portanto, que todas são aluminosilicatos (argilominerais) com traços de Ti e Fe, indicativos da presença de minerais micáceos e ferro-titaníferos (PROVIS, 2002). A confirmação será obtida por análise por difração de raios X.

Observa-se nas micrografias a $1300 \mathrm{X}$ de magnificação a predominância de partículas lamelares, morfologia característica dos filossilicatos, como a caulinita ${ }^{8}$. Algumas amostras apresentam micropartículas dispersas, indicativo de elevada finura, 
como é o caso do caulim KDR, enquanto outras revelam formação de grandes aglomerados de partículas, como é o caso do KAP, do KCS e do KPX.

Figura 4 - (a) Micrografia obtida em MEV da amostra KAP (1300 X). (b) Respectivo espectro de EDS

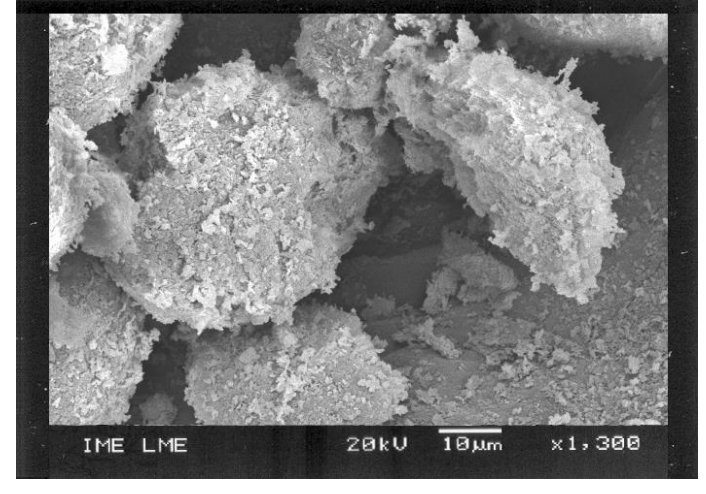

(a)

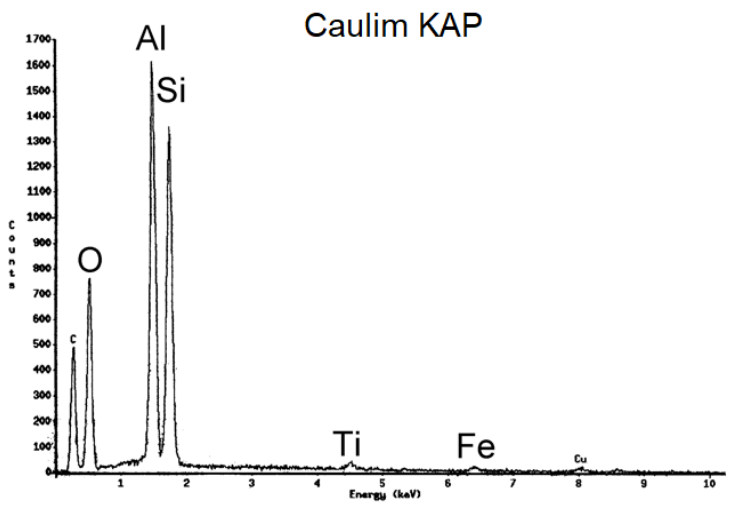

(b)

Fonte: Os autores

Figura 5 - (a) Micrografia obtida em MEV da amostra KCT (1300 X). (b) Respectivo espectro de EDS

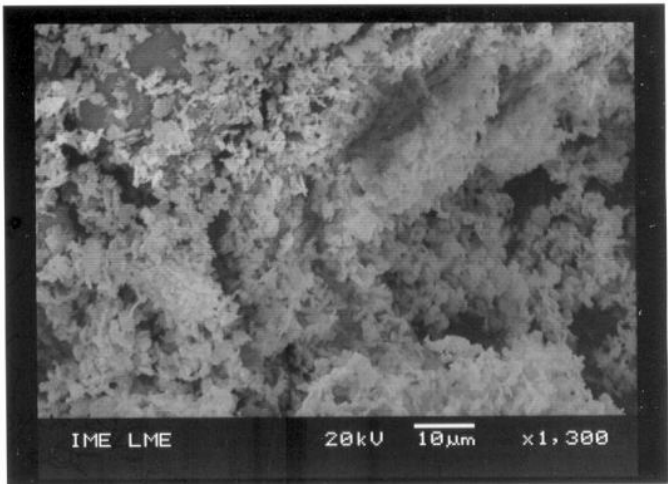

(a)

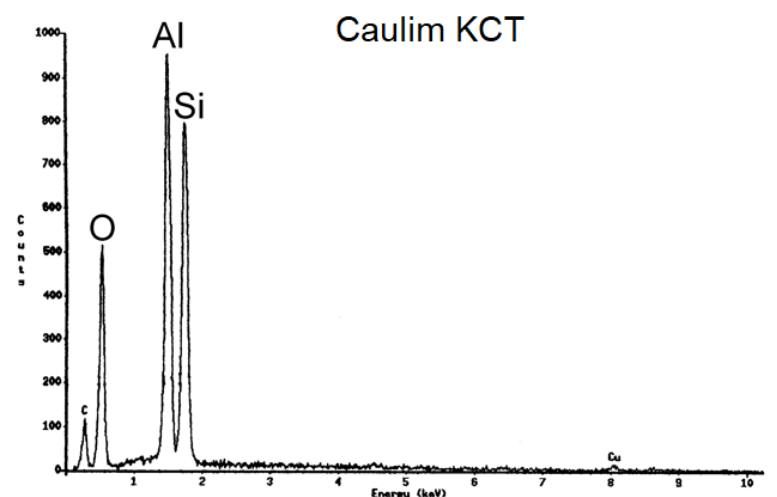

(b)

Fonte: Os autores

Figura 6 - (a) Micrografia obtida em MEV da amostra KCS (1300 X). (b) Respectivo espectro de EDS 


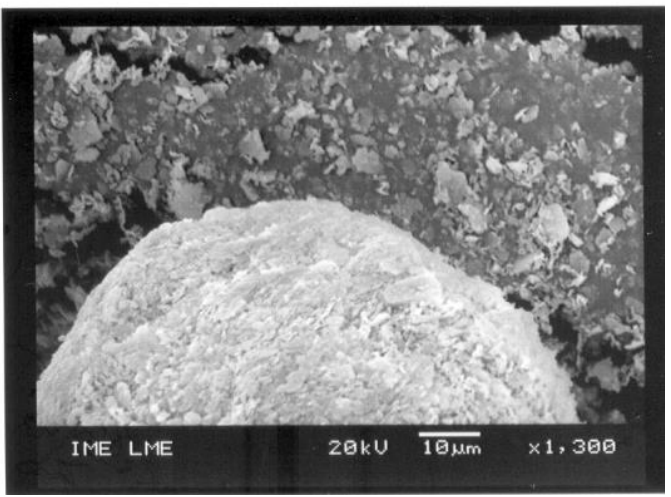

(a)

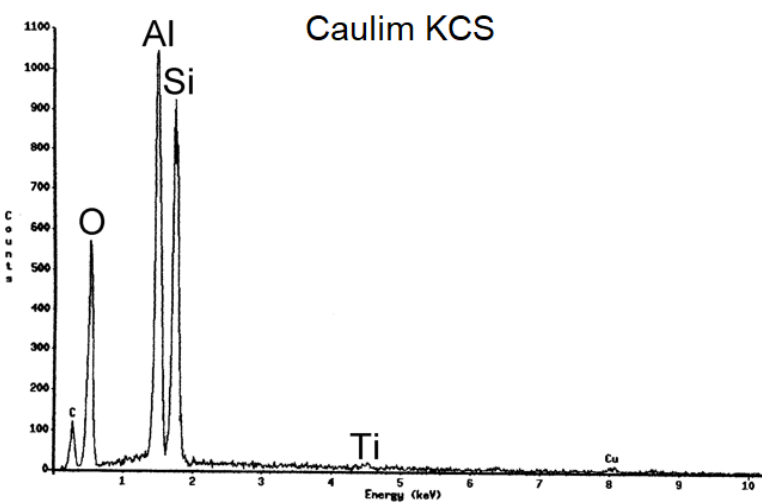

(b)

Fonte: Os autores

Figura 7 - (a) Micrografia obtida em MEV da amostra de KDR (1300 X). (b) Respectivo espectro de EDS

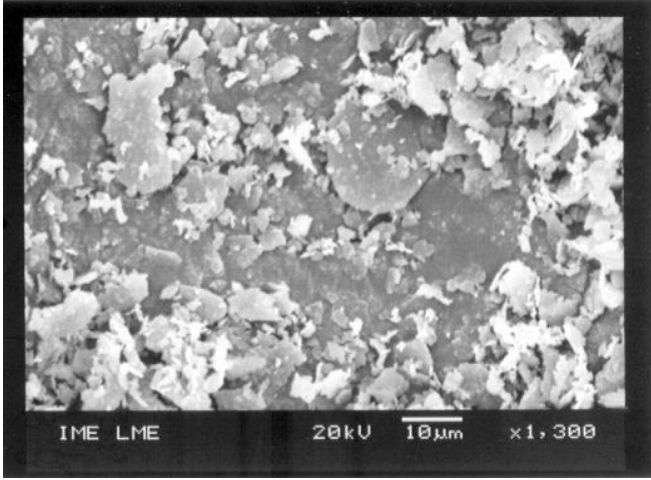

(a)

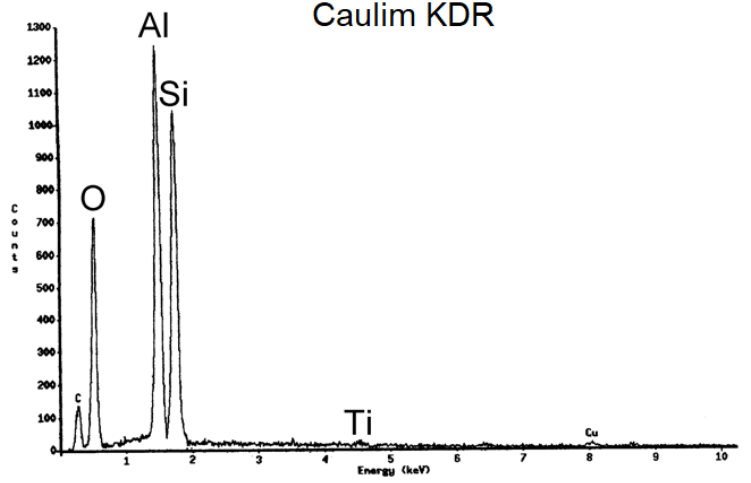

(b)

Fonte: Os autores

Figura 8 - (a) Micrografia obtida em MEV da amostra KFL (1300 X). (b) Respectivo espectro de EDS

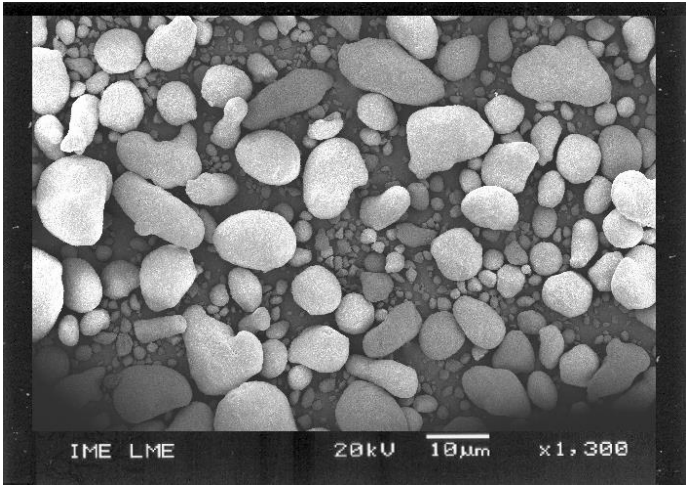

(a)

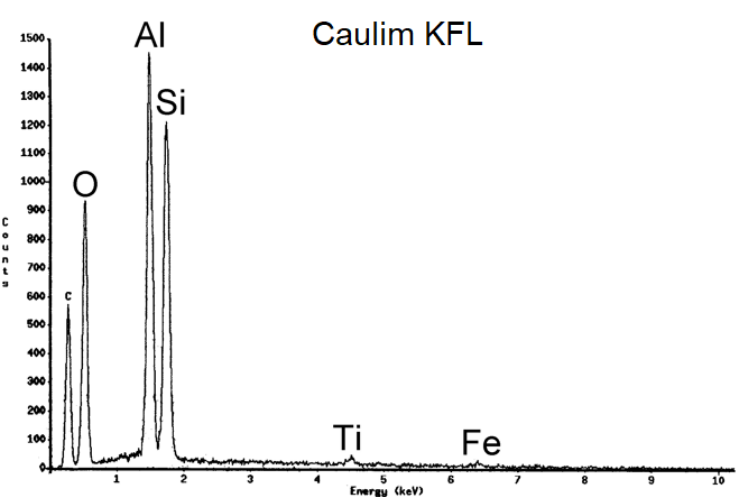

(b)

Fonte: Os autores

Figura 9 - (a) Micrografia obtida em MEV da amostra KPX (1300 X). (b) Respectivo espectro de EDS 


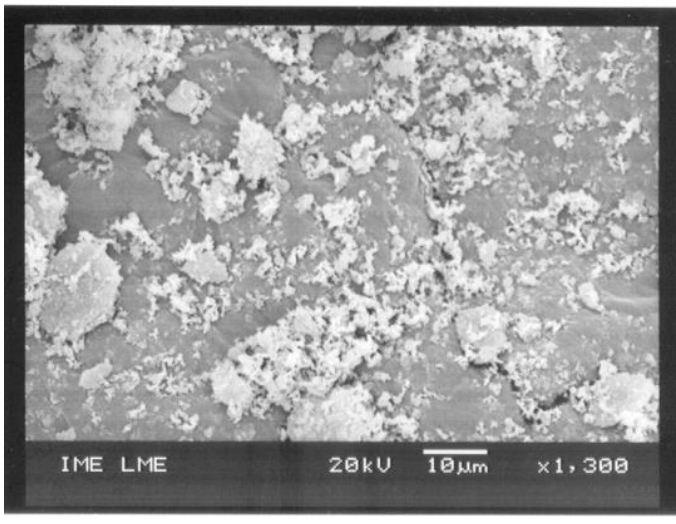

(a)

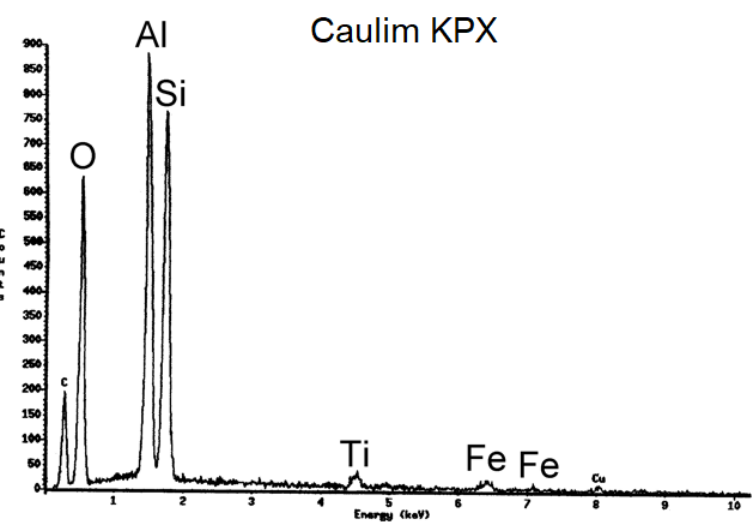

(b)

Fonte: Os autores

Figura 10 - (a) Micrografia obtida em MEV da amostra KStd (1300 X). (b) Respectivo espectro de EDS

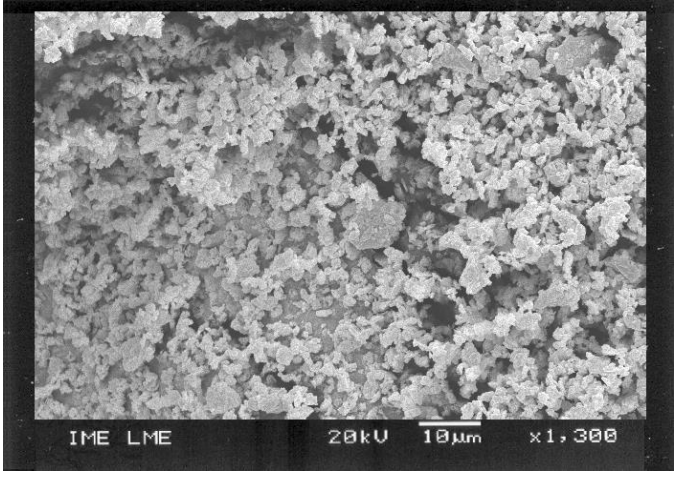

(a)

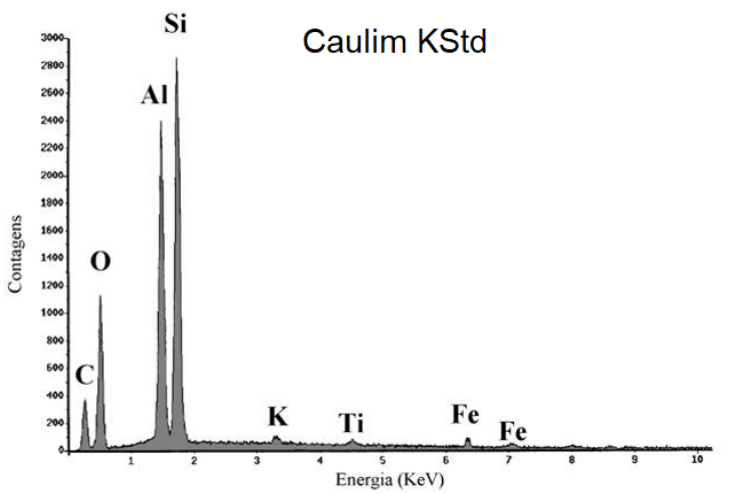

(b)

Fonte: Os autores

No caso dos caulins KCT e KFL, ambos apresentam grandes aglomerados, com dimensão máxima acima de 4,8 mm (vide Fig 3). Neste último, os aglomerados têm aparência de seixo rolado. Parecem compactos em baixas magnificações (1300 X), mas em observação mais detalhada $(5000 \mathrm{X})$, confirma-se sua formação por partículas individuais de caulinita (Fig 11).

As Figuras 12 a 18 mostram difratogramas de raios $\mathrm{X}$ das amostras de rejeito de caulim, antes e depois da calcinação a $850^{\circ} \mathrm{C} / 2 \mathrm{~h}$, para análise da amorfização.

Os resultados mostram que a caulinita é o principal composto presente em todas as amostras analisadas. Pela baixa intensidade dos picos característicos das impurezas, infere-se sobre a alta qualidade desses rejeitos (ou subprodutos) e seu potencial aproveitamento para diversas aplicações nobres. Minerais contaminantes como quartzo $\left(\mathrm{SiO}_{2}\right)$ e anatásio $\left(\mathrm{TiO}_{2}\right)$ foram identificados em quase todas as amostras. Outros 
argilominerais, como muscovita, também foram identificados nas amostras de caulim KFL e KPX, assim como ilita, no metacaulim Padrão, MKStd.

Figura 11 - Micrografias MEV das amostras de rejeito de caulim (5000 X). (a) KAP, (b) KFL, (c) KPX, (d) KStd

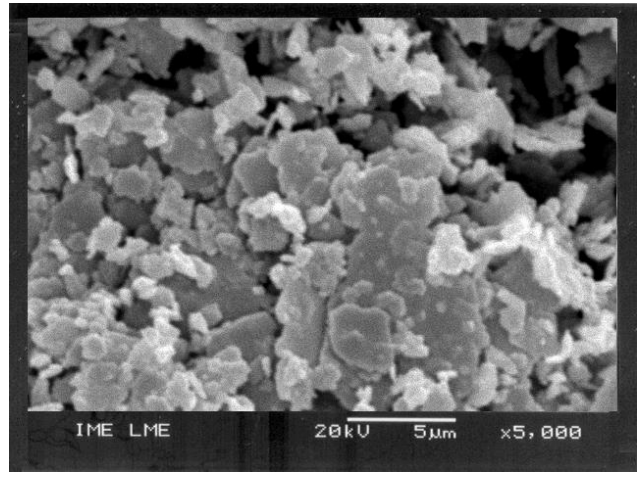

(a)

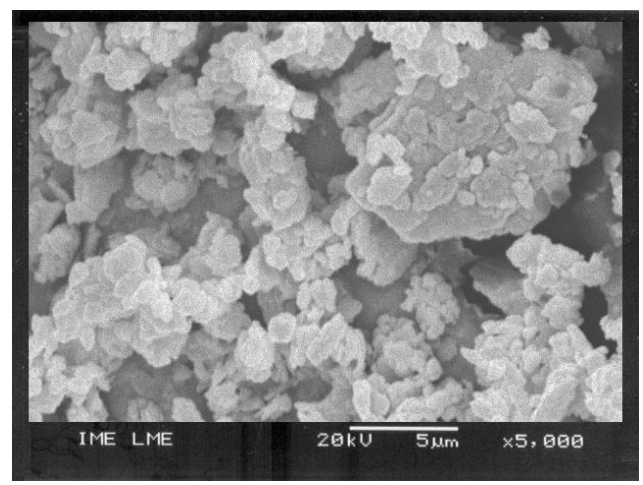

(c)

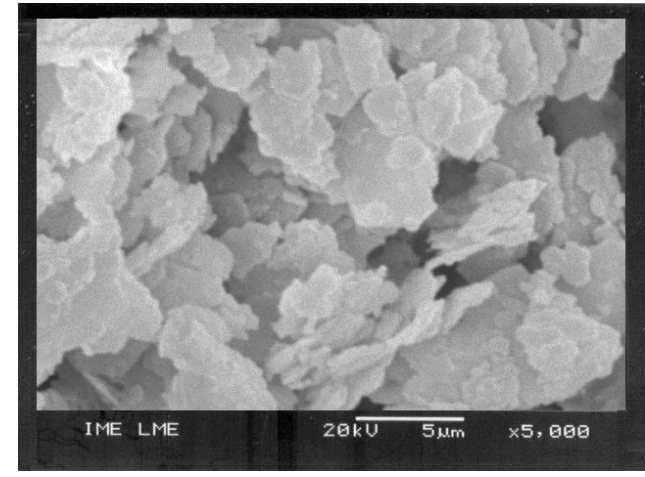

(b)

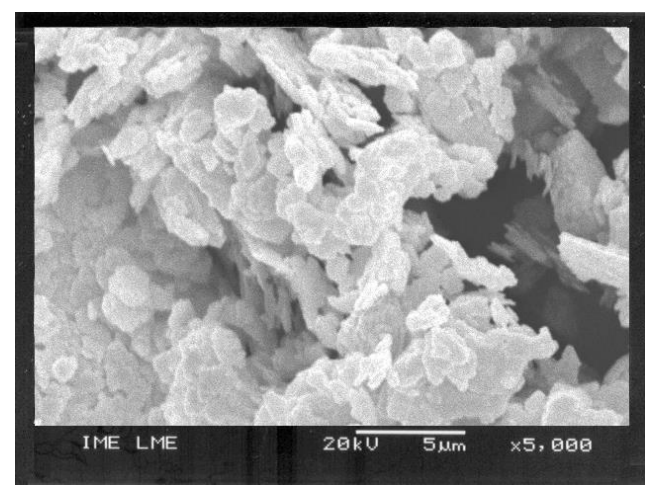

(d)

O caulim KFL se destaca entre os demais por apresentar elevado grau de cristalinidade (picos de caulinita de elevada intensidade). Como o objetivo é "quebrar" a cristalinidade da caulinita, através da calcinação do caulim entre 700 e $900{ }^{\circ} \mathrm{C}$, é provável que esta amostra exija maiores temperaturas e tempos de calcinação para garantir bons resultados.

Após calcinação, os picos característicos da caulinita sofrem perda de intensidade ocasionada pela desidroxilação das folhas octaédricas da caulinita (camada gibsita), objetivo do processo. No entanto, busca-se a sua total supressão, o que teoricamente é a garantia de que adequada desordem estrutural foi obtida. Como é na camada gibsita, onde são encontrados os sítios ocupados pelo alumínio, são estes os pontos da estrutura susceptíveis ao ataque químico. No caso da calcinação a $850^{\circ} \mathrm{C} / 2 \mathrm{~h}$, as amostras de caulim KCT, KCS e KCT ainda apresentam caulinita, como mostrado pelos seus difratogramas após calcinação. O curioso é que o processo de calcinação foi eficiente para o caulim 
KFL, de maior cristalinidade. Para eliminar quaisquer traços de caulinita residual é preciso aumentar o tempo de calcinação ou a temperatura. Contudo, todo cuidado deve ser tomado para que tais condições não ultrapassem a barreira de ativação para a conversão de metacaulinita em espinélio silício-alumínio (SCRIVENER et al., 2018; BERNAL et al., 2013). Sabe-se que, acima de 900-950 ${ }^{\circ} \mathrm{C}$ há cristalização de mulita, o que torna o material inerte e impróprio para o uso que se propõe (BERNAL et al., 2013).

Figura 12 - (a) DRX da amostra do caulim KAP. (b) Calcinado a $850{ }^{\circ} \mathrm{C} / 2 \mathrm{~h}(\mathrm{MKAP})$

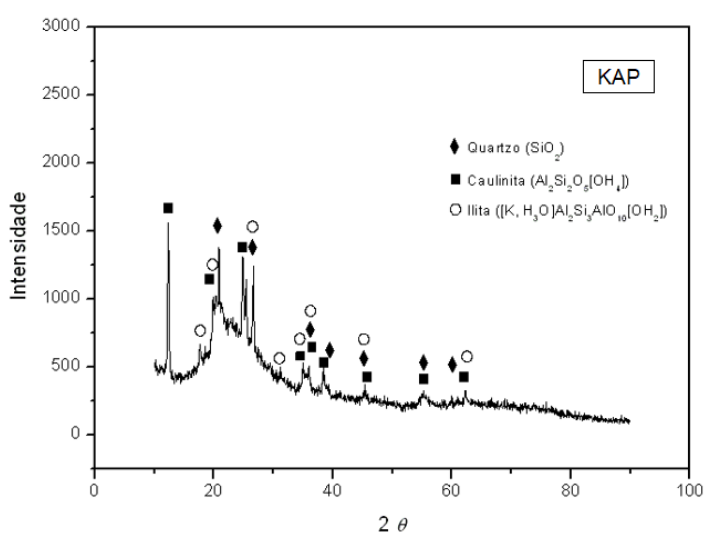

(a)

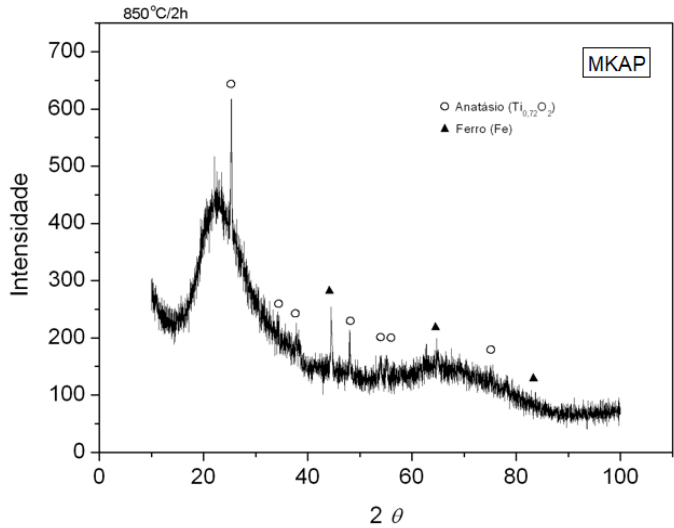

(b)

Fonte: Os autores

Figura 13 - (a) DRX da amostra do caulim KCT. (b) Calcinado a $850{ }^{\circ} \mathrm{C} / 2 \mathrm{~h}(\mathrm{MKCT})$

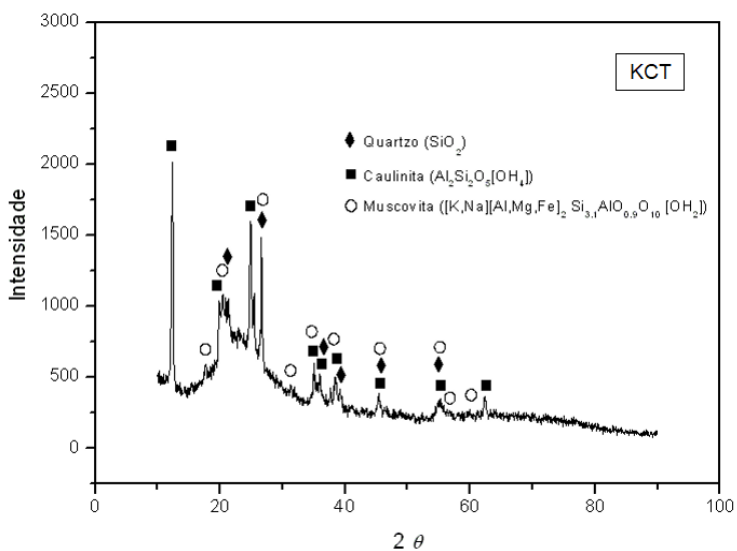

(a)

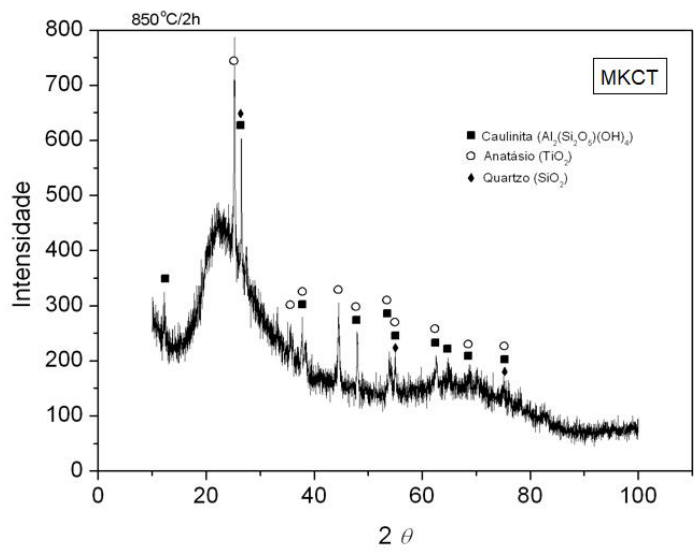

(b)

Fonte: Os autores

Figura 14 - (a) DRX da amostra do caulim KCS. (b) Calcinado a $850{ }^{\circ} \mathrm{C} / 2 \mathrm{~h}$ (MKCS) 


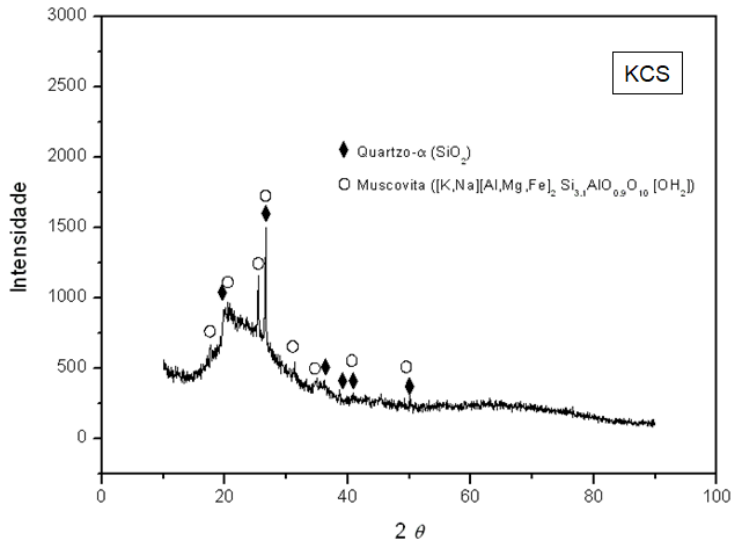

(a)

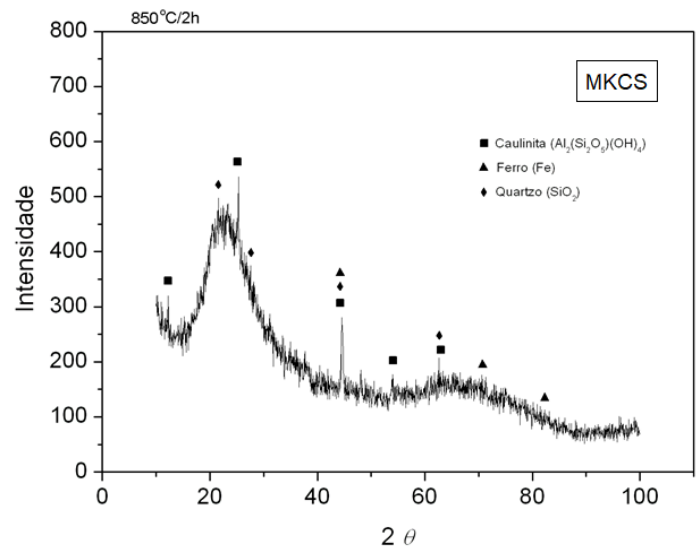

(b)

Fonte: Os autores

Figura 15 - (a) DRX da amostra do caulim KDR. (b) Calcinado a $850{ }^{\circ} \mathrm{C} / 2 \mathrm{~h}(\mathrm{MKDR})$

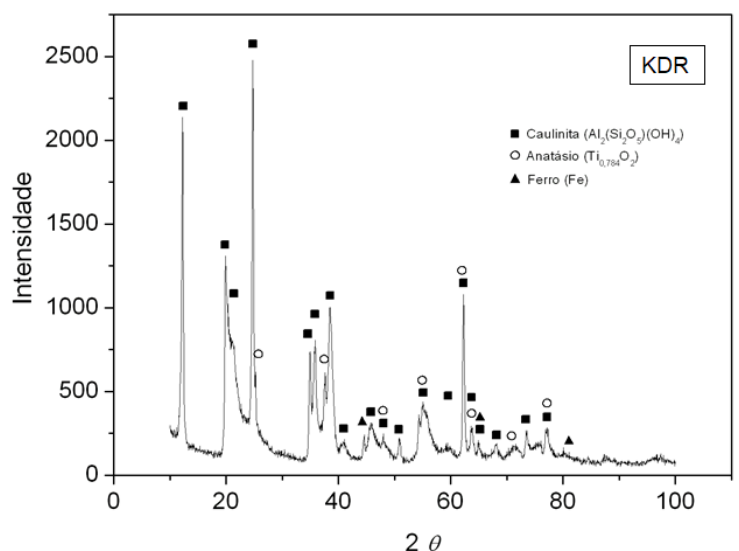

(a)

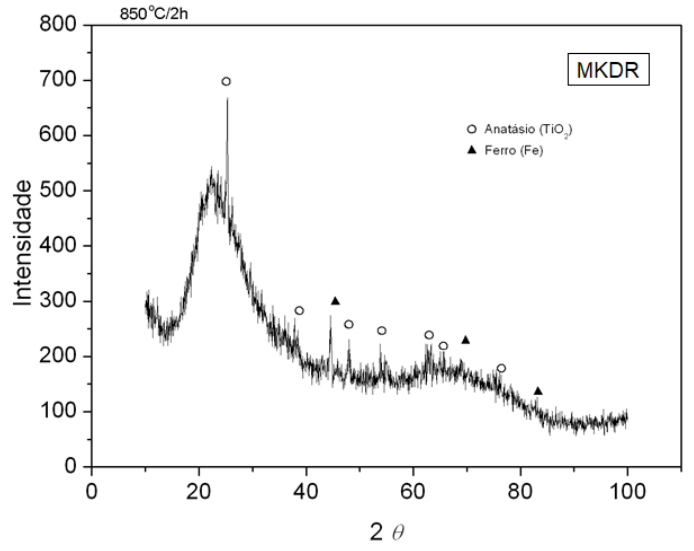

(b)

Fonte: Os autores

Figura 16 - (a) DRX da amostra do caulim KFL. (b) Calcinado a $850{ }^{\circ} \mathrm{C} / 2 \mathrm{~h}$ (MKFL)

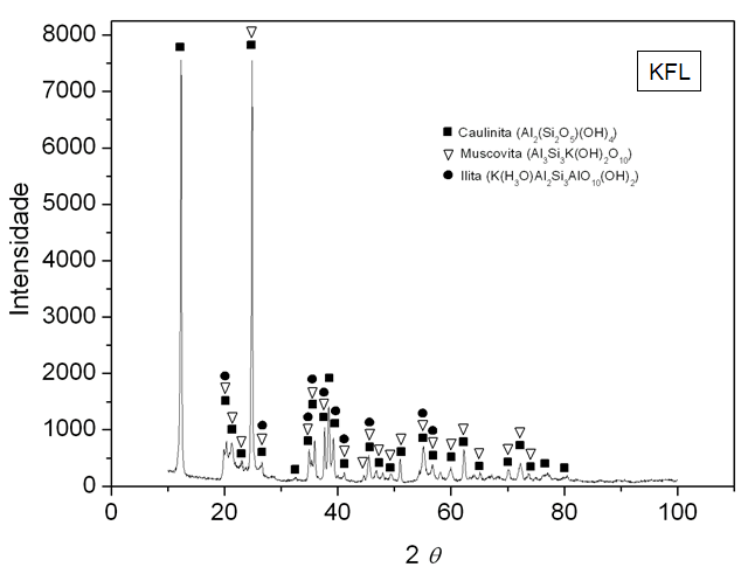

(a)

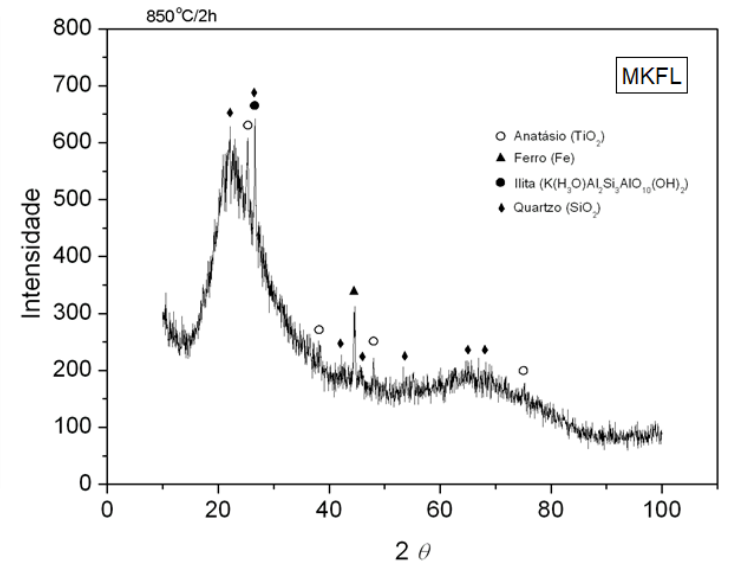

(b)

Fonte: Os autores

Figura 17 - (a) DRX da amostra do caulim KPX. (b) Calcinado a $850{ }^{\circ} \mathrm{C} / 2 \mathrm{~h}(\mathrm{MKPX})$ 


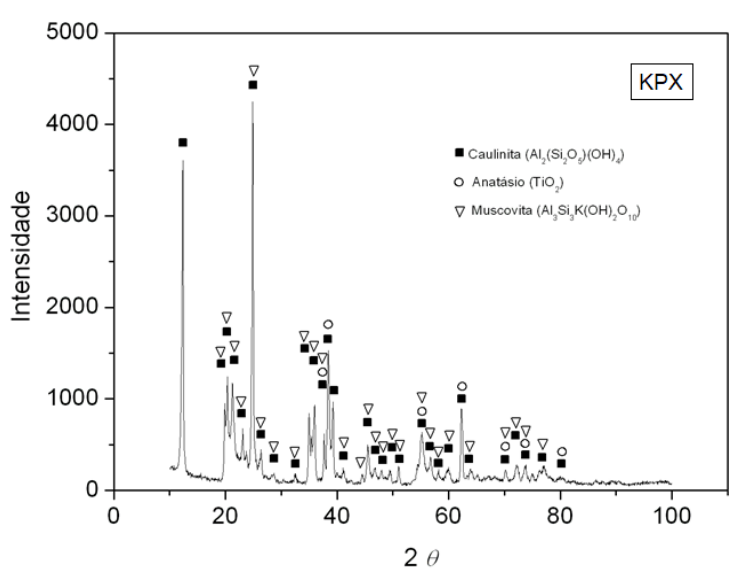

(a)

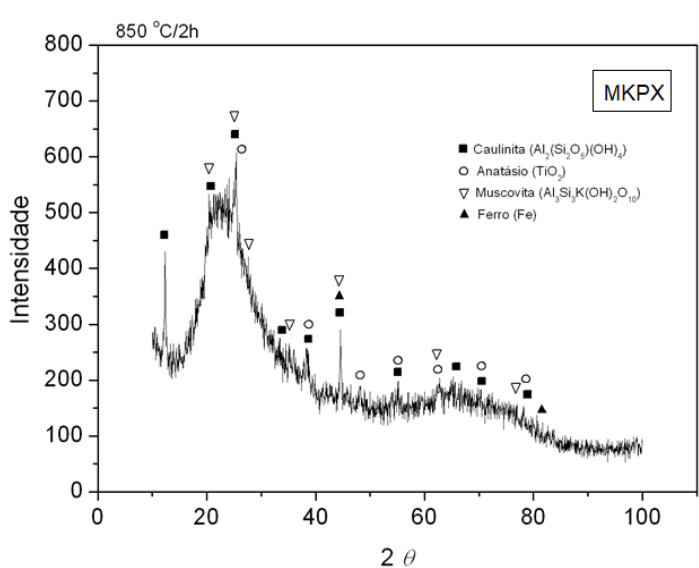

(b)

Fonte: Os autores

Figura 18 - DRX da amostra do Metacaulim Padrão (MKStd)

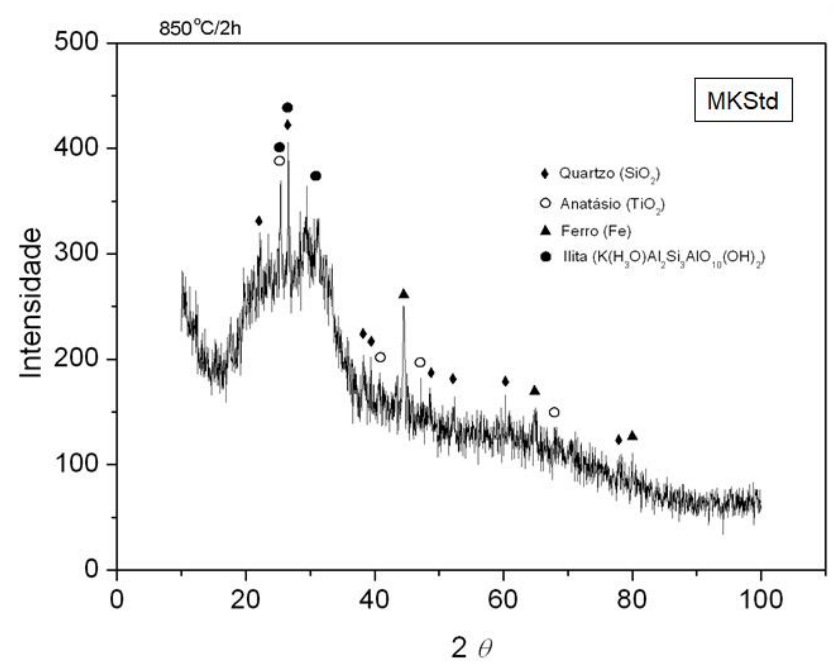

Fonte: Os autores

A questão, no entanto, é saber qual o grau de desordem alcançado no processo de calcinação, já que a reatividade do metacaulim pode diferir entre amostras calcinadas sob diferentes condições, mas com espectros de DRX idênticos (KARATAS et al., 2019).

O processo de calcinação não só remove água quimicamente ligada, presente na estrutura da caulinita, como obriga a estrutura a sofrer acomodações, motivadas pela variação da energia livre armazenada. Existe, portanto, uma condição que conduz à máxima energia armazenada e que garante o mais alto grau de desordem à estrutura (MORSY et al., 1997).

Desta forma, cada caulim requer uma condição específica de calcinação para fornecer o máximo grau de desordem à sua estrutura. Características como grau de cristalinidade da caulinita e de empilhamento de suas partículas (tamanho e forma dos aglomerados) e a coexistência com outros argilominerais e impurezas como o quartzo, 
mica, feldspato e minerais ferro-titaníferos, podem interferir na geopolimerização e reduzir o desempenho do geopolímero obtido (DAVIDOVITS, 1994).

As superfícies específicas das amostras de rejeito de caulim calcinadas a 850 ${ }^{\circ} \mathrm{C} / 2 \mathrm{~h}$ são mostradas na Tabela 4 . Como pode ser observado, há diferenças significativas nos valores de superfície específica, corroborando com os resultados de distribuição granulométrica por peneiramento, ao passo que a massa específica, em torno de $2,6 \mathrm{~g} / \mathrm{cm}^{3}$, infere sobre a similaridade de composição química.

Tabela 4 - Caracterização física das amostras de caulim calcinadas a $850{ }^{\circ} \mathrm{C} / 2 \mathrm{~h}$

\begin{tabular}{c|c|c}
\hline Amostra & $\mathrm{SE}\left(\mathrm{m}^{2} / \mathrm{kg}\right)$ & $\mathrm{ME}\left(\mathrm{g} / \mathrm{cm}^{3}\right)$ \\
\hline MKAP & 108,21 & 2,60 \\
\hline MKCT & 507,49 & 2,60 \\
\hline MKCS & 224,72 & 2,61 \\
\hline MKDR & 1272,54 & 2,58 \\
\hline MKFL & 686,81 & 2,58 \\
\hline MKPX & 419,41 & 2,60 \\
\hline MKStd & 1306,11 & 2,57 \\
\hline
\end{tabular}

Fonte: Os autores

A sistemática de comparação entre diferentes matérias primas para uso como precursor geopolimérico consiste, normalmente, na adequação das suas características físico-químicas e na manutenção das relações molares da formulação tomada como referência.

Neste trabalho preliminar, as diferentes amostras foram apenas calcinadas sob uma mesma condição $\left(850^{\circ} \mathrm{C} / 2 \mathrm{~h}\right)$ e empregadas na formulação de referência, na mesma quantidade em massa e sem nenhum outro beneficiamento. Entretanto, devido à diferença de granulometria (finura), a consistência inicial das argamassas variou muito com os diferentes tipos de rejeito de caulim calcinado (metacaulim). Já que o teor de água foi mantido constante, por fazer parte da formulação de referência, optou-se por determinar a relação aglomerante/agregado que fornecesse a melhor condição de mistura, com a menor dispersão de resultados de resistência. As Figuras 19a e 19b mostram o resultado comparativo de ensaios de consistência (flow table - NBR 9997:2015) e de resistência à compressão, respectivamente, realizados com três dos metacaulins utilizados neste estudo. A relação aglomerante:agregado que forneceu os melhores resultados de resistência à compressão foi que a que apresentou consistência mais próxima da consistência Normal, recomendada pela NBR 9997:2015 (165 $\pm 5 \mathrm{~mm})$. Portanto, a relação 1:2 foi escolhida para todos os experimentos. 
Figura 19 - Argamassas geopoliméricas obtidas com rejeitos de caulim calcinado de diferentes tipos. Variação da consistência (a) e da resistência à compressão (b), em função da relação aglomerante/agregado

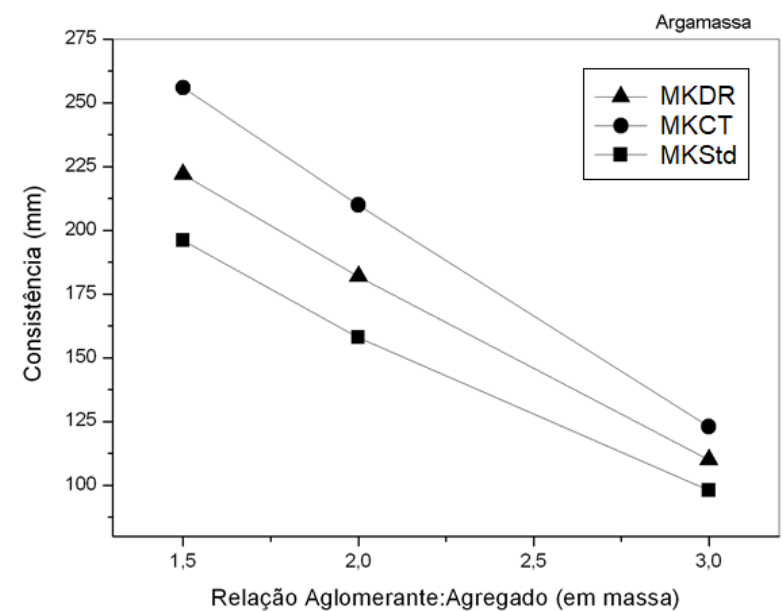

(a)

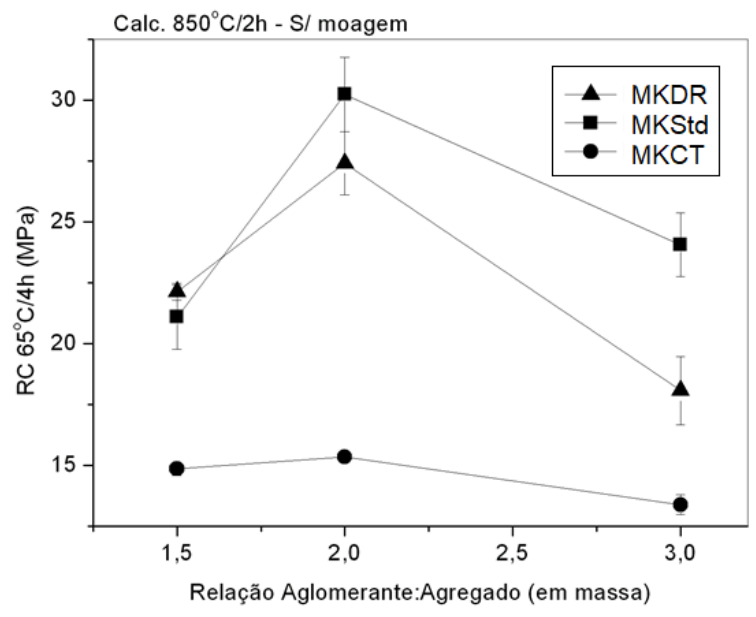

(b)

Fonte: Os autores

A mistura das argamassas foi realizada de acordo com a NBR 11982:2017. A cura dos corpos de prova (CP) foi realizada em estufa a $65^{\circ} \mathrm{C}$ por 4 horas. $\mathrm{O}$ topo dos $\mathrm{CP}$ foi vedado com filme de PVC para evitar evaporação da água durante a cura térmica. Foi feito resfriamento ao ar até a temperatura ambiente, em seguida retirado o filme de PVC e desmoldado o CP. A Figura 20 mostra a taxa de resfriamento ao ar, no ambiente do laboratório. A temperatura ambiente era atingida em aproximadamente uma hora.

Os resultados comparativos de resistência à compressão são mostrados na Figura 21. Houve correlação direta com o que foi observado na caracterização dos rejeitos de caulins/metacaulins. A amostra MKDR, com perfil granulométrico mais próximo da amostra padrão, apresentou o melhor resultado. A surpresa foi o MKFL, cuja resistência foi pouco abaixo do MKDR mas que apresentou granulometria bem mais grosseira, com passagem pela peneira $\mathrm{n}^{0} 200$, de apenas $5 \%$ da massa total. Já as demais amostras calcinadas, apresentaram deficiência da ordem de $50 \%$ da resistência obtida com a amostra padrão.

Figura 20 - Taxa de resfriamento do CP no molde 


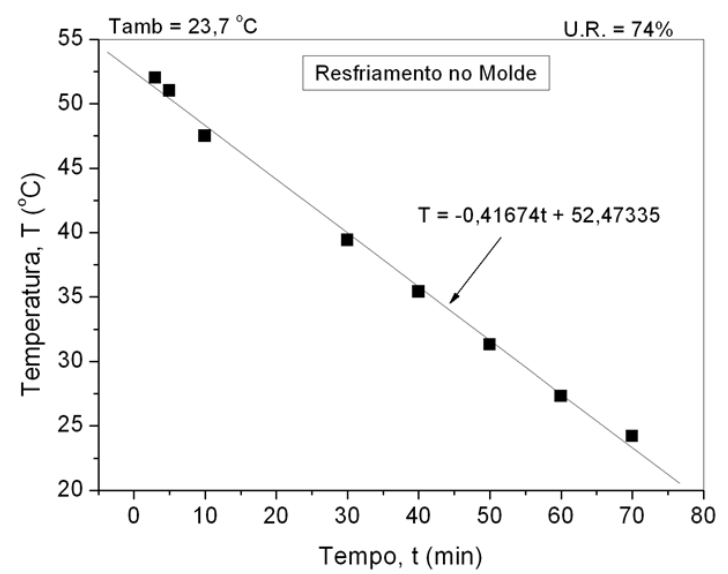

Fonte: Os autores

Figura 21 - Resistência à compressão com 5 h de idade, em função do tipo de rejeito de caulim calcinado. Corpos de prova de argamassa curados em estufa a $65^{\circ} \mathrm{C} / 4 \mathrm{~h}$. Cura térmica

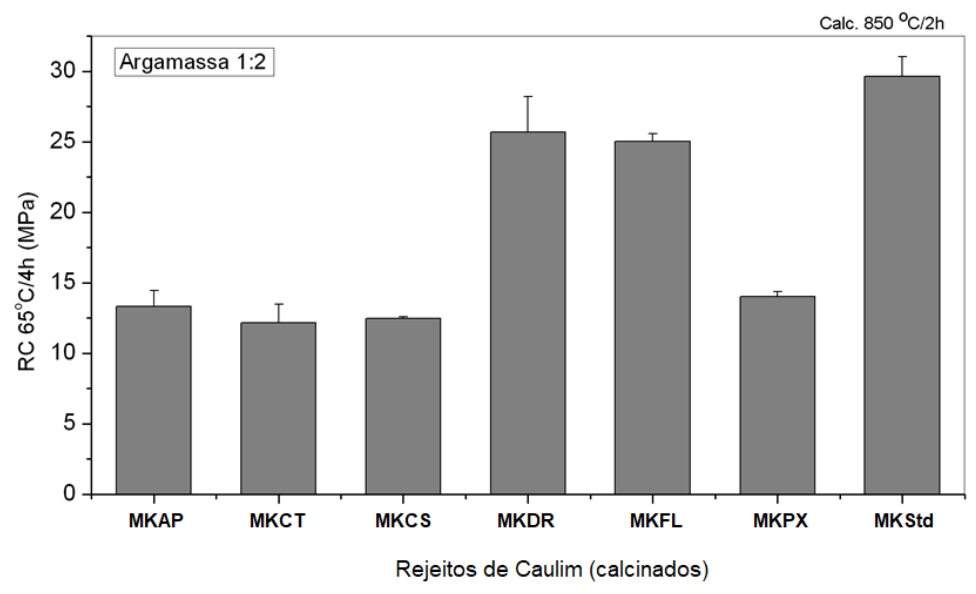

Fonte: Os autores

Em complementar a este trabalho, é proposta a implementação de um programa de calcinação por tempos mais extensos e/ou temperaturas diferentes, a fim de garantir a total conversão de caulinita em metacaulinita, e o beneficiamento posterior por moagem dos pós, visando assim, aumentar a área específica/reatividade e proporcionar melhores resultados e o aproveitamento de mais tipos de rejeitos de caulim.

\section{CONCLUSÕES}

Diversos ensaios foram realizados com objetivo de investigar a potencialidade de uso dos seis diferentes tipos de rejeitos de caulim recebidos, para uso como agente precursor geopolimérico. A caracterização físico-química e microestrutural permitiu diferenciá-los entre si facilmente, através da granulometria, composição mineralógica, 
tamanho, forma e disposição das partículas individuais de caulinita. Como se tratou de estudo comparativo, uma amostra padrão foi tomada como referência, um metacaulim industrializado empregado em estudos anteriores e que apresenta propriedades satisfatórias para uso em geopolímeros estruturais.

Os ensaios exploratórios realizados com as amostras calcinadas sob condições específicas de tempo e temperatura e sem qualquer outro beneficiamento mostrou que apenas as amostras de rejeito de caulim dos tipos KDR e KFL apresentaram conformidade para uso depois de calcinadas. As demais apresentaram baixa reatividade na formulação utilizada nos estudos, notadamente identificada pelas baixas áreas específicas e presença, em alguns metacaulins, de caulinita residual. Sugere-se que o aumento do tempo de calcinação e o beneficiamento por moagem possa inferir reatividade suficiente nas demais amostras, para que o aproveitamento seja mais ostensivo.

\section{AGRADECIMENTOS}

Os autores agradecem à FAPERJ e à CAPES pelo apoio financeiro aos alunos (bolsas), ao IME/SE-4 pelas análises de MEV/EDS e à Genesis/PUC-Rio pelas análises de DRX.

\section{REFERÊNCIAS}

AMERICAN SOCIETY FOR TESTING \& MATERIALS. Standard specification for coal fly ash and raw or calcined natural pozzolan for use in concrete. ASTM-C618-19, 2019.

BARANI, K.; KALANTARI, M. Recovery of kaolinite from tailings of Zonouz kaolinwashing plant by flotation-flocculation method. Journal of Materials Research and Technology. v. 7, n. 2, p. 142-148, 2018.

BERNAL, S. A.; GUTIERREZ, R. M.; RODRÍGUEZ, E. D. Alkali-activated materials: cementing a sustainable future. Ingeniería y Competitividad, v. 15, n. 2, p. 211-223, 2013.

CAMPOS, A. P.; MONTEIRO, C. C.; SILVA, J. P. A. Sumário Mineral - 2018, Agência Nacional de Mineração. Brasília - DF: 2018. (Disponível em: https://www.gov.br/anm/pt-br/centrais-de-conteudo/publicacoes/serie-estatisticas-eeconomia-mineral/sumario-mineral/sumario-mineral-brasileiro-2018). Acesso em $20 \mathrm{de}$ outubro de 2021. 
DAVIDOVITS, J. Geopolymers inorganic polymeric new materials. Journal of Thermal Analysis, v. 37, p. 1633, 1991.

DAVIDOVITS, J.; Properties of geopolymer cements. In: Proceedings of: the First International Conference Alcaline Cements and Concretes. Ucrânia, 1994.

KARATAS, M.; DENER, M.; MOHABBI, M.; BENLI, A. A study on the compressive strength and microstructure characteristic of alkali-activated metakaolin cement.

Revista Matéria, v. 24, n. 4, e-12507, 2019.

KIVENTERÄ, J.; PERUMAL, P.; YLINIEMI, J.; ILLIKAINEN, M. Mine tailings as a raw material in alka-li activation: A review. International Journal of Minerals, Metallurgy and Materials, v. 27, p. 1009-1020, 2020.

LIMA, V. M. E.; FUCALE, S.; ESTOLANO, A. M. L.; BERENGUER, R. A.; LIMA, N. B.; CABRAL, L. C., et al. Concrete precast rejects - treatment, characterization, and application in new concrete as recycled aggregate. Conjecturas, v. 21, n. 4, p. 142-181, 2021.

MORSY, M. S.; EL-ENEIN, S. A.; HANNA, G. B. Microstructure and hydration characteristics of artificial pozzolana-cement pastes containing burnt kaolinite clay.

Cement and Concrete Research, v. 27, n. 9, p. 1307-1312, 1997.

PROVIS J. L. Alkali activated materials. Cement and Concrete Research, v. 114, p. 40-48, 2018.

SANTOS, P.S. Tecnologia de argilas aplicada às argilas brasileiras: Fundamentos. São Paulo: Edgard Blücher, 1975.

SANTOS, P. S. Ciência e tecnologia de argilas: Aplicações. $2^{\text {a }}$ ed. revisada e ampliada, São Paulo: Edgard Blücher, 1992.

SCRIVENER, K. L.; JOHN, V. M.; GARTNERC, E. M. Eco-efficient cements: potential economically viable solutions for a low- $\mathrm{CO}_{2}$ cement-based materials industry. Cement and Concrete Research, v. 114, p. 2-26, 2018. 